\title{
The Impact on the Level of Anxiety and Pain of the Training before Operation Given to Adult Patients
}

\author{
Neziha Karabulut ${ }^{1}$, Funda Cetinkaya ${ }^{2}$ \\ ${ }^{1}$ Department of Surgical Nursing, School of Nursing, The Faculty of Health Science, Ataturk University, \\ Erzurum, Turkey \\ ${ }^{2}$ Department of Surgical Nursing, School of Nursing, Aksaray University, Erzurum, Turkey \\ E-mail: nezihekarabulut@hotmail.com \\ Received April 3, 2011; revised May 13, 2011; accepted July 9, 2011
}

\begin{abstract}
Aim: the aim oh this study was to detrmine the effects of different training programs implemented before inguinal hernia operation on the pre- and post-operation anxiety level of and pain level the patient. Material and Method: this quasi experimental study was carried out with inguinal hernia patients 18 - 60 years who were hospitalized in the General Surgery Clinic of Hospital of Atatürk University and Süleyman Demirel Medical Centre in Erzurum for inguinal hernia operation. The study data were collected between November 2007-May 2008 from a total of 90 patients. 30 patients were in the control group, 30 were in the video (VCD) training group, and 30 were in the booklet training group. Data were collected by means of a questionnaire about the patients and the inventory of state anxiety fort he adult. In collecting data, patient introduction form and Spielberger'in State-Trait Anxiety Inventory, and visual analogue scale (VAS) were used. In data assessment, T-test, Pearson correlation test, Mauchly's variance analysis, Anova for repeated measures tests and Bonferroni Correction Analysisi were used. Results: in control, booklet and VCD groups, in group Situational Constant Anxiety score average was found significant in each three time periods $(p<0.001)$. When the pain situations of the patients after operation was considered, the distinction in Visual Analogue Scale and Verbal Rating Scala values of two groups in all measurement times was found significant $(p<$ 0.001). Conclusion: in the conclusion of the study, it was found out that the given education effective on level of pain and anxiety score for experimental groups of patients.
\end{abstract}

Keywords: Preoperative, Preparing, Patient, Anxiety, Pain, Operation

\section{Introduction}

Being healthy is defined not only as the absence of disease and disability, but also as a complete well being in terms of physical, social and mental state. The continuity of the inner environment of the human organism is dependent on the individual's physiological and psychological balance. The main objective of nursing care is to provide maintenance of the state of health, by preserving the continuity of the inner environment, and to help in restoring the balance lost in the state of illness [1,2].

People sometimes have to be hospitalized for the maintenance and continuity of their health $[3,4]$. The process of hospitalization, regardless of the reason, causes different reactions in different people, including adverse reactions such as anxiety, fear, and depression.
The patient feels anxiety as a result of the physical effects imposed by the disease as well by the change of environment imposed by hospitalization. These factors, which may cause anxiety in the hospitalized individual, include the anxiety of receiving painful treatment, being away from his/her family, losing his/her job, being in an alien environment, and encountering unknown devices and procedures. The anxiety of undergoing an operation also feeds into this list of factors and constitutes a significant source of anxiety $[3,5,6]$. Anesthesia, operation, and some invasive interventions invoke real and unreal fears. For the patient, an operation implies pain, loss of independence, and distortion of body image, and each of these factors is perceived as a threat. The individual feels anxiety when he/she faces this type of threat that is rected to the order of his/her body or life $[7,8]$. 
Anxiety is defined as a state that emerges as a result of a response against threats that may disrupt bodily balance, or a failure in restoring the lost balance [9]. Anxiety has several negative effects on an organism, and one of these effects is pain. Pain is an abstract concept and affects the life quality of the individual in a negative way by preventing the individual from carrying out daily activities. The degree or nature of pain can only be described by the individual affected by this state [10-13]. Pain is the primary complaint of post-operative patients [10]. Severity of postoperative pain is related to several factors. Operation type is one of these [14-16]. Pain is an individual and subjective experience, and anxiety is the most important determinant of postoperative pain. Acute pain and acute anxiety are usually seen together, with decreasing pain reducing the severity of the pain response [17]. Studies have shown that anxiety increases pain and the need for pain killers in the postoperative period, and also reduces pain resistance [18]. In research carried out by Özalp et al. [19]. on 99 female patients, patients with depression and high anxiety levels were found to experience more pain and to need more pain killers.

Intense anxiety experienced in the pre-operative period increases the intensity of pain in the postoperative period and makes pain control difficult [20]. As high levels of pain are associated with the anxiety and fear level of the patient, providing education is one of the most important strategies that can be used by the nurse for reducing postoperative pain [21]. Research has demonstrated that anxiety levels of the patient and his/her family, and the information required by each, are comparable [22,23]. Anxieties of patients in general have been found to be associated with lack of information. Since education reduces anxiety, preoperative education and informing is the first step in the psychological preparation of patients [21,24]. Pre-operative patient education reduces patient anxiety and helps in overall pain control [17].

In research carried out in a general surgery clinic, it was determined that $31 \%$ and $14 \%$ of the patients were not informed about pre-operative and post-operative processes, respectively, whereas $95 \%$ of the patients wanted to receive information about the processes to be performed [25].

In a study carried out by Luck et al. examined the effect of pre-colonoscopy video-modeled training on the anxiety and information levels of patients, and concluded that the average anxiety score was $41.6(37.1-46.1)$ in patients who received video-modeled training and 60.8 (56.6 - 65.0) in patients who did not receive this training. [26] Educational programs designed according to the needs of patients also are found to help satisfy the pa- tient's need for knowledge, to decrease anxiety, to shorten the discharge time, and to allow discharge with less cost $[22,26,27]$.

\section{Materials and Methods}

The study was conducted between November 2007 and May 2009. It was carried out quasi-experimentally on patients between 18 - 60 years, who were hospitalized for inguinal hernia operation in the General Surgery Clinic of Research Hospital of Atatürk University and Süleyman Demirel Medical Centre in Erzurum. Considering the age group to which the inventory could be applied, and their ability to understand, the study included only those patients between 18 - 60 years of age.

Sample selection was not performed in this study due to the limited time and small number of cases. Patients were selected from the population using a nonprobability sampling method, and they were categorized into experimental and control groups by a nonprobability/random sampling method. It is generally accepted that the number of samples should be at least 30 in experimental and control groups $[28,29]$. Therefore, the data were collected until the number of patients had reached 90 . This allowed sorting of 30 patients into the control group, 30 into the VCD training group, and 30 into the booklet training group. The groups were examined in the order of the control group, VCD group, and booklet group. The study included adult patients (and their mothers) who were to undergo inguinal hernia operations, were to be hospitalized in the clinic for at least 2 days, were between 18 - 60 years of age, did not have any apparent primary chronic disease, were not on antidepressants, could read, write, and communicate in Turkish, and whose hospital attendants were their mothers. Questionnaires were prepared by the researcher, in line with the information in the literature $[24,26]$. In the first section, there were 11 questions related to the identifying characteristics of the patients. These questions sought answers regarding the patient's "age; gender; hospital experience; operative experience; if yes, the number of previous operations; place of residence; education status, career status, hospital experience, operative experience, and health insurance". The second section included the anxiety levels of the patients, which were evaluated by means of the revised State Anxiety Inventory (STAI) developed by Spielberger. The adaptation of STAI to Turkish, as well as the reliability and validity studies, were done by Öner and Le Compte. The reliability coefficients, as determined by alpha correlations in the adaptation of STAI to Turkish, were 0.83 and 0.92 , while that for the present study was 0.72 . The reliability coefficients determined in the STAI for children were 0.82 for the state anxiety in- 
ventory and 0.72 in the present study [9]. The third section included the Pain Follow-up Form, the Visual Analogue Scale, and the Verbal Rating Scale values. The Visual Analogue Scale (VAS) is a scale developed by Price et al. (1983) and measures patient's pain severity. VAS is a scale in which two ends are named differently on a vertical and horizontal line measuring $10 \mathrm{~cm}(0=$ no pain, $10=$ severest pain). The patient is asked to mark on this line the point corresponding to the pain severity he/she feels. The distance between the marked point and the lowest end on the line $(0=$ no pain) is measured and the numerical value found designates the patient's pain severity [30]. Before the study, a pilot study was carried out in order to determine whether the questions and information booklet were understandable. For this purpose, 15 patients ( 5 from the control group, 5 from the VCD training group, and 5 from the booklet training group) were included. State anxiety inventory and questionnaires were given to the patients in all three groups 48 hours prior to the operation. The VCD and booklet groups were given training 24 hours before the operation. Inventories (state anxiety inventory for adults) were given to all three groups 24 hours before the operation and 24 hours after the operation. In all three groups, in the control and experiment groups, post-operative Visual Analogue Scale and Verbal Rating Scale tests were applied at 1/2, 1, 2, 3, 4, 5, 6, 7, 12, 24 hours. The study was initiated after making the necessary corrections in the questionnaire and training materials, in line with the data obtained from a pilot study. These pilot data were not included in the current study results. Questionnaire and inventories (identifying characteristics of the patients, and State Anxiety Inventory for adults) were given 48 and 24 hours pre-operatively and 24 hours postoperatively in the control group.

Upon admission to the clinic, the VCD training group was given the questionnaire and inventories and, on the same day, the group watched the VCD that had been prepared by the researcher, in line with the literature and with consultation and support from the staff of the Faculty of Communication at Atatürk University. The VCD group was shown the VCD by the researcher. Later, a place was provided for the patients (and their mothers) who wanted to watch the VCD again. Accordingly, the patients watched the VCD in the computer room of the general surgery clinic. The total duration of the VCD is 12 minutes. The State Anxiety Inventory for adults was given 24 hours before and 24 hours after the operation. In order to increase the effectiveness of the VCD training and to make it more realistic, the nurse responsible for the clinic was educated beforehand and she participated in the recording of the VCD.

The booklet training group was also given the ques- tionnaire form (identifying characteristics of the patient and the mother) as well as the State Anxiety Inventory for adults, 48 hours before the operation. On the same day, booklets were distributed and the questions were answered. The training was given individually in an empty room and lasted for 20 - 30 minutes. The booklet group was given training once by the researcher. The State Anxiety Inventory for adults was given 24 hours before and 24 hours after the operation, and postoperative Visual Analogue Scale and Verbal Rating Scale was applied post-operatively at 1/2, 1, 2, 3, 4, 5, 6, 7, 12, 24 hours. In the study, anxiety levels were evaluated at three time periods (48 hour before the operation, 24 hours before the operation, and 24 hours after the operation). Patients who undergo unguinal hernia operation are generally discharged after 48 hours, as these are not complicated operations. In previous studies, anxiety measurements were done before and after the training.31 The present study aims to perform a deeper analysis.

The patients in the control group were given a small amount of information regarding the operation in the pre-operative clinical routine (pre- and post-operative nutrition, hour of admission to the operating room, duration of hospitalization).

\subsection{The VCD and Booklet Included the Following Topics}

\subsubsection{Physical Structure of the Hospital}

The outer appearance, entrance, and general clinic of the hospital were introduced.

\subsubsection{Hospital Life}

Information was provided about meal hours and procedures, visiting, attendance, and communication.

\subsubsection{Information about the Operation}

The nurse and other health personnel in the clinic were introduced. The devices used in the hospital and operating room, including masks, gloves, and caps, were introduced and their functions were explained. How the patient would be brought to the operating room, and by which health personnel, were shown. Information was given about the environment of the operating room, the devices and procedures used there, as well as the patient's transport to the recovery room after the completion of the operation. The procedures to be performed after the patient regained consciousness were also detailed. During the training, information was provided regarding the operation; the probe, IV catheter, etc. that might be involved, the probable complications that could develop, and the procedures that would be followed in case of pain. The booklet contains drawings and photo- 
graphs that reflect the hospital environment.

The contents of the video and booklet are identical.

The researcher conducted the study by visiting the clinic every day to find out if any new patients who meet the eligibility criteria of the study had been hospitalized.

\subsection{Statistical Analysis}

The data in the study were used to form a database and were tabulated using SPSS Windows 10.0 software. Mauchly's variance analysis, Bonferroni correction analysis, and Pearson correlation test were used in the evaluation of the data $[9,28]$.

\subsection{Ethical Consideration}

Consent was obtained from the hospital and department before initiating the study. In addition, the patients were told about the aims of the study and the procedures to follow. In addition, any questions they had were answered. Afterwards, the patients were asked for verbal permission. Upon their consent, the study was initiated.

\section{Results}

The age average of patients included in the research was $45.60 \pm 11.08$ in the control group, $43.80 \pm 14.30$ in the booklet group, and $44.96 \pm 12.80$ in the VCD group. In the control group, $56.7 \%$ were male patients, while $53.3 \%$ and $56.7 \%$ in the booklet and VCS groups respectively were females. Gender distribution differences were not statistically significant among the three groups ( $p>$ 0.05 ) (Table 1). In terms of education status, 50\%, $73.3 \%$ and $76.7 \%$ of the control group, booklet group, and VCD group, respectively, were primary school graduates. The difference between the education status of patients in the control, booklet and VCD group was found to be statistically significant $(p<0.05)$ (Table 1). In terms of the marital status of patients, $90 \%, 83.3 \%$, and $90 \%$ of the control group, booklet group, and VCD group, respectively, were married. The difference between the marital status of patients in all three groups was found to be statistically significant $(p<0.05)$. Distribution among the patients in terms of operation experience revealed that $50 \%, 56.7 \%$, and $53 \%$ of the patients in the control group, booklet group, and VCD group, respectively, had a previous operation experience. The difference between the three groups was not statistically significant $(p>0.05)$ (Table 1). The mean state anxiety scores of the patients in the control group were $38.13(\mathrm{SD}=8.00)$ at 48 hours before the operation, 47.13 $(\mathrm{SD}=10.07)$ at 24 hours before the operation, and 32.96 $(\mathrm{SD}=5.92)$ at 24 hours after the operation. However, the mean state anxiety scores of the patients in the VCD training group were $47.00(\mathrm{SD}=6.00)$ at 48 hours before the operation, $26.56(\mathrm{SD}=2.89)$ at 24 hours before the

Table 1. Comparison of the identifying characteristics of patients in Control, Booklet, and VCD groups.

\begin{tabular}{|c|c|c|c|c|c|c|}
\hline Identifying Characteristics & \multicolumn{2}{|c|}{ Control Group } & \multicolumn{2}{|c|}{ Booklet Group } & \multicolumn{2}{|c|}{ VCD Group } \\
\hline Age Average & \multicolumn{2}{|c|}{$\begin{array}{c}45.60 \pm 11.08 \\
F=0.181\end{array}$} & \multicolumn{2}{|c|}{$\begin{array}{c}43.80 \pm 14.30 \\
\mathrm{SD}=2\end{array}$} & \multicolumn{2}{|c|}{$\begin{array}{c}44.96 \pm 12.80 \\
p>0.05\end{array}$} \\
\hline & \multicolumn{2}{|c|}{ Control Group } & \multicolumn{2}{|c|}{ Booklet Group } & \multicolumn{2}{|c|}{ VCD Group } \\
\hline Gender & Number & $\%$ & Number & $\%$ & Number & $\%$ \\
\hline \multirow[t]{2}{*}{ Male } & 17 & 56.7 & 14 & 46.7 & 13 & 43.3 \\
\hline & \multicolumn{2}{|c|}{$x^{2}=0.044$} & \multicolumn{2}{|c|}{$\mathrm{SD}=2$} & \multicolumn{2}{|c|}{$p>0.05$} \\
\hline \multicolumn{7}{|l|}{ Education Status } \\
\hline Primary School & 15 & 50.0 & 22 & 73.3 & 23 & 76.7 \\
\hline \multirow[t]{2}{*}{ High School } & 15 & 50.0 & 8 & 26.7 & 7 & 23.3 \\
\hline & \multicolumn{2}{|c|}{$\mathrm{x}^{2}=10.0$} & \multicolumn{2}{|c|}{$\mathrm{SD}=2$} & \multicolumn{2}{|c|}{$p<0.05$} \\
\hline \multicolumn{7}{|l|}{ Marital Status } \\
\hline Married & 27 & 90.0 & 25 & 83.3 & 27 & 90.0 \\
\hline Single & 3 & 10.0 & 5 & 16.7 & 3 & 10.0 \\
\hline & \multicolumn{2}{|c|}{$x^{2}=5.37$} & \multicolumn{2}{|c|}{$\mathrm{SD}=2$} & \multicolumn{2}{|c|}{$p<0.05$} \\
\hline
\end{tabular}


operation, and $24.46(\mathrm{SD}=2.84)$ at 24 hours after the operation. The mean state anxiety scores of the patients in the booklet group were $42.30(\mathrm{SD}=7.73)$ at 48 hours before the operation, $26.80(\mathrm{SD}=3.36)$ at 24 hours be- fore the operation, and $24.66(\mathrm{SD}=2.26)$ at 24 hours after the operation. The difference in the state anxiety scores of the patient in the groups according to time was statistically significant in the control group $(p<0.001)$ and in the VCD training group $(p<0.001)$, and was significant in the booklet training group $(p<0.001)$ (Table 2$)$.

State anxiety levels of the patients in the control group 24 hours before the operation was found to be higher than were those observed at other time measurement points. State anxiety levels of the children in the VCD training group 48 hours before the operation were found to be higher than were those observed at the other time measurement points. The differences presented in Table 2 results from the measurement performed 48 hours before the operation (according to Bonferroni correction analysis). State anxiety levels of mothers 48 hours before the operation were high in the video and booklet training groups. In the evaluation of the patient's mean intergroup state anxiety scores 48 hours before the operation, the average score was 37.06 ( $\mathrm{SS}=8.00)$ in the control group, $47.00(\mathrm{SS}=6.00)$ in the $\mathrm{VCD}$ group, and $42.30(\mathrm{SS}=$
$7.73)$ in the booklet group. The mean state anxiety scores at 24 hours before the operation were $47.13(\mathrm{SS}=10.07)$ in the control group, $26.56(\mathrm{SS}=2.89)$ in the VCD group, and $26.80(\mathrm{SS}=3.36)$ in the booklet group. The scores at 24 hours after the operation were $32.96(\mathrm{SS}=5.92)$ in the control group, 24.46 ( $\mathrm{SS}=2.84$ ) in the VCD group, and 24.66 ( $\mathrm{SS}=2.26)$ in the booklet group. The differences between the groups in favor of the VCD group 24 hours before and after the operation were statistically significant at all three time points $(p<0.001,48$ hours before the operation; $p<0.001,24$ hours before and after the operation). As a result of these findings, it was determined that the training given primarily with VCD (24 hours before and after the operation) was more effective in reducing the anxiety levels of patients (Table 3 ).

In Table 4, a significant difference was found between VRS and VAS levels of the control, booklet, and VCD groups at all measurement times $(p<0.001)$.

\section{Discussion}

In the maintenance and improvement of a person's health status, the educational role of the nurse has a considerable significance in activating the control mechanisms in states of illness. The nurse assumes the role of an expert

Table 2. Comparison of the scale application times and state anxiety scores of patients in the control, booklet and VCD groups.

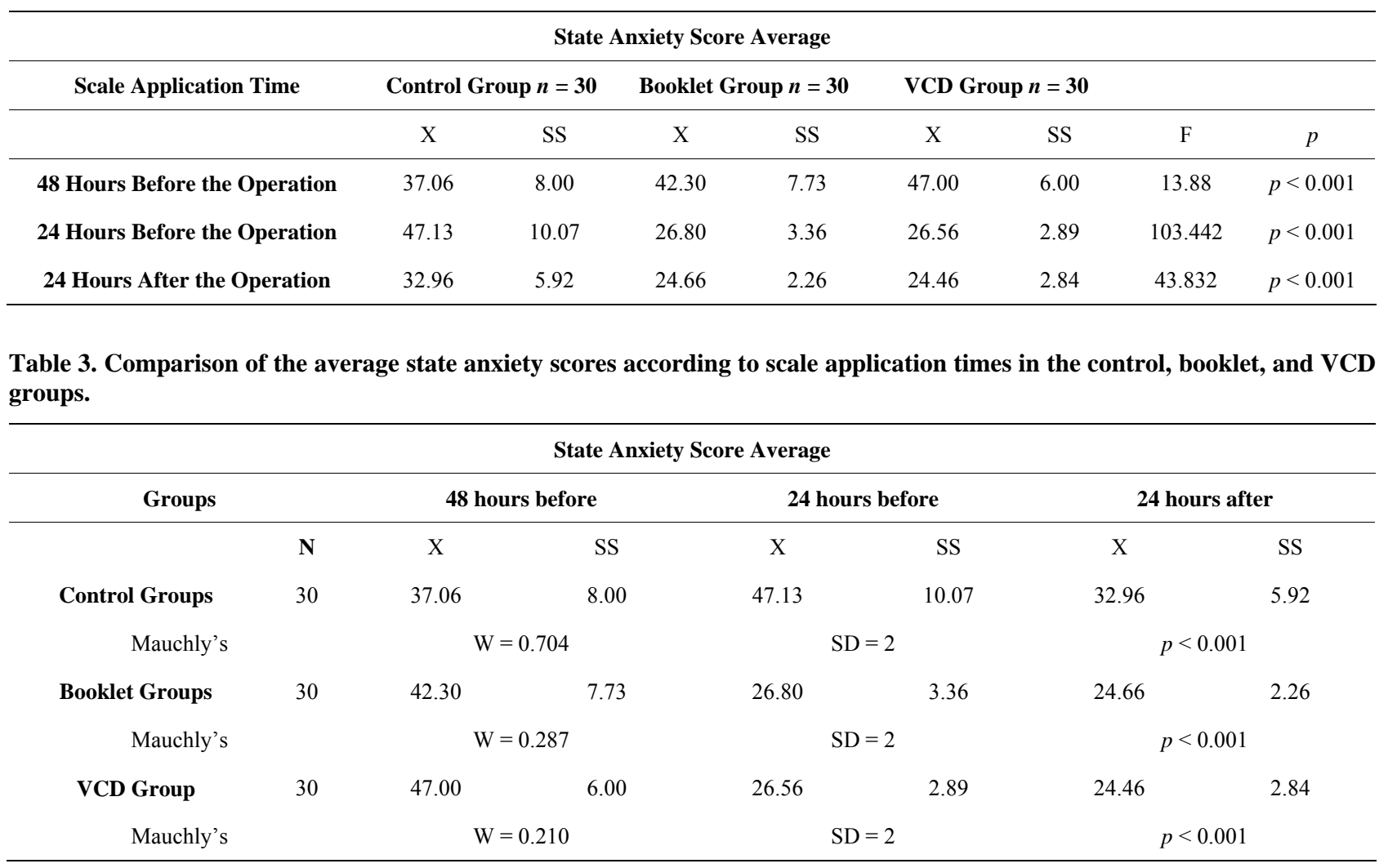


Table 4. Comparison of VRS and VAS Values of Patients in the control, booklet, and VCD groups according to Measurement Times.

\begin{tabular}{|c|c|c|c|}
\hline Time & GROUP & $\mathrm{X} \pm \mathrm{SS}$ VRS & $\mathrm{X} \pm$ SS VAS \\
\hline & Control & $4.773 \pm 0.44$ & $86.066 \pm 8.50$ \\
\hline \multirow[t]{3}{*}{ 1/2 hour } & Booklet & $4.266 \pm 0.44$ & $79.100 \pm 10.24$ \\
\hline & VCD & $4.166 \pm 0.59$ & $76.200 \pm 7.48$ \\
\hline & Control & $4.100 \pm 0.30$ & $75.833 \pm 8.80$ \\
\hline \multirow[t]{3}{*}{$\mathbf{1}^{\text {st }}$ hour } & Booklet & $3.466 \pm 0.50$ & $62.600 \pm 12.86$ \\
\hline & VCD & $3.533 \pm 0.50$ & $62.900 \pm 11.66$ \\
\hline & Control & $3.400 \pm 0.49$ & $61.866 \pm 9.50$ \\
\hline \multirow[t]{3}{*}{$2^{\text {nd }}$ hour } & Booklet & $2.733 \pm 0.63$ & $44.833 \pm 12.55$ \\
\hline & VCD & $2.766 \pm 0.62$ & $45.166 \pm 13.33$ \\
\hline & Control & $3.133 \pm 0.62$ & $55.666 \pm 12.86$ \\
\hline \multirow[t]{3}{*}{$3^{\text {rd }}$ hour } & Booklet & $2.466 \pm 0.50$ & $38.266 \pm 11.16$ \\
\hline & VCD & $2.866 \pm 0.62$ & $37.366 \pm 11.33$ \\
\hline & Control & $2.900 \pm 0.75$ & $45.900 \pm 13.67$ \\
\hline \multirow[t]{3}{*}{$4^{\text {th }}$ hour } & Booklet & $2.066 \pm 0.44$ & $31.466 \pm 9.75$ \\
\hline & VCD & $2.266 \pm 0.44$ & $29.766 \pm 9.56$ \\
\hline & Control & $2.500 \pm 0.68$ & $39.533 \pm 13.32$ \\
\hline \multirow[t]{3}{*}{$5^{\text {th }}$ hour } & Booklet & $2.100 \pm 0.30$ & $28.533 \pm 7.78$ \\
\hline & VCD & $1.900 \pm 0.60$ & $25.733 \pm 6.96$ \\
\hline & Control & $2.633 \pm 0.76$ & $39.966 \pm 12.12$ \\
\hline \multirow[t]{3}{*}{$6^{\text {th }}$ hour } & Booklet & $2.033 \pm 0.31$ & $25.866 \pm 6.50$ \\
\hline & VCD & $1.566 \pm 0.50$ & $22.500 \pm 5.85$ \\
\hline & Control & $2.366 \pm 0.66$ & $33.066 \pm 11.34$ \\
\hline \multirow[t]{3}{*}{$7^{\text {th }}$ hour } & Booklet & $1.833 \pm 0.46$ & $23.233 \pm 7.01$ \\
\hline & VCD & $1.433 \pm 0.50$ & $19.233 \pm 5.46$ \\
\hline & Control & $2.200 \pm 0.40$ & $30.100 \pm 8.90$ \\
\hline \multirow[t]{3}{*}{$12^{\text {th }}$ hour } & Booklet & $1.200 \pm 0.40$ & $14.733 \pm 5.53$ \\
\hline & VCD & $1.366 \pm 0.49$ & $11.133 \pm 3.13$ \\
\hline & Control & $1.866 \pm 0.62$ & $24.400 \pm 9.18$ \\
\hline \multirow[t]{3}{*}{$24^{\text {th }}$ hour } & Booklet & $1.133 \pm 0.34$ & $11.333 \pm 5.39$ \\
\hline & VCD & $1.300 \pm 0.53$ & $7.733 \pm 2.19$ \\
\hline & & $\mathrm{F}=79.200 \quad p=0.000$ & $F=68.447$ \\
\hline
\end{tabular}

by determining the educational needs of both the patient and his/her family and by providing these individuals with extensive information and education [32].

At the end of the study, education and marital status of patients in the control, booklet, and VCD groups were found to be significant, and these were observed to be similar in terms of gender and age. Comparable characteristics among patients are a desirable condition in terms of providing homogeneity. According to the identifying characteristics of patients, the difference between state 
anxiety score averages was statistically significant $(p<$ $0.05)$. Inter-group state anxiety score averages of patients revealed that the difference between groups 48 hours after the operation was statistically significant (Table 2).

Both at 24 hours before and 24 hours after the operation, the difference between the groups was statistically significant $(p<0.001)$ (Table 2). This significance was associated with the increase in the low state anxiety score average in the control group 24 hours before the operation. After the operation, there was a reduction in the state anxiety levels, due to the decrease in stress resulting from anticipation of the operation. As state anxiety is related to momentary events, the state anxiety score average was initially high in the booklet and VCD group, but decreased 24 hours before the operation as a conesquence of the education given to the patients. Because the patient knew that he/she would be discharged after the operation, state anxiety averages decreased even more and were statistically different in all three groups. When the intra-group state anxiety score average of patients was examined over time, the score average in the control group 48 hours before the operation was 37.06, and it increased to 47.13 in this group 24 hours before the operation. In the booklet group, while the state anxiety score average 48 hours before the operation was 42.00 , it decreased to 26.80 in the this group 24 hours before the operation. Similarly, this score decreased from 47.00 to 26.56 in the VCD group 24 hours before the operation. After the operation, state anxiety score average decreased in all three groups. In line with these results, the comparison of state anxiety score averages of in-group patients according to time was found to be statistically significant $(p<0.001)$ (Table 3). This finding reveals that education given by different education methods was able to reduce the state anxiety score average levels of patients and that it had proven to be effecttive. According to the obtained results, state anxiety score averages of patients in the booklet and VCD groups, who had received a planned education, were lower than were those of patients who had not received any education.

In the literature, it is stated that people remember $10 \%$ of what they read, $20 \%$ of what they hear, $30 \%$ of what they see, and $50 \%$ of what they both see and hear, provided that time is held constant [33]. In research carried out by Akkaş [34], education given to patients in preoperative period was found to reduce their anxiety level. In the study of Asilioglu and Celik [35], The effect of preoperative education on anxiety of open cardiac surgery patients, it is shown that the anxiety level of the educated group is lower than the control group. In the research carried out by Yorulmaz and Özbayır [36], who investigated "the pre-operative and post-operative anxi- ety level of patients who would undergo laparoscopic cholecystectomy", state-trait anxiety score averages before the operation were found to be higher than were those measured after the operation. There was no statistically significant difference found between pre-operative and post-operative state-trait anxiety scores $(p<0.05)$. In the study of Roth-Isigkeit and his friends, named Development and evaluation of a video program for presentation prior to elective cardiac surgery, it is concluded that The findings obtained in this study are consistent with the results of the studies indicating that training with visual tools is more effective than with other types of material [37].

Doering S. Behensky and his friends stated that "Preoperative presentation of videotapes is used as an adjunct method for the preparation of patients prior to surgery" in their study named. Videotape preparation of patients before hip replacement surgery improves mobility after three months.

A marked decrease was observed in the state anxiety score averages of patients who had been recipients of an informative nursing approach. In the current study, the results demonstrated that an informative nursing approach was effective in reducing state and trait anxiety $(p$ $<0.05$ ). An examination of the post-operative pain levels of patients seen in the present work revealed a significant difference in the VRS levels between control and experimental groups at all measurement points $(p<0.001)$. Similarly, at all measurement points, a significant difference was found in the VAS levels between the two groups $(p<0.001)$. VAS pain scores in the control group of the present study were high at the first measurement point and showed higher scores continuously through to the last time point. The VAS pain scores of patients in the booklet and VCD groups were lower at the beginning and decreased even further by the end of the experimenttal period, compared to the control group. As the education given to the patients had a similar positive effect on pain, pain scores in the first and last measurement were lower in both the booklet and VCD group. This finding was in agreement with a previous study by Özberksoy and Özbayır [39] on the "effect of preoperation informative and educational nursing approaches on the postoperation pain and anxiety level in patients with breast cancer". In this earlier study, VAS values with lower scores were also recorded in the education group compared to the control group.

Sjöling et al. [40] have investigated the "effect of preoperation information on anxiety level, post-operative pain and pain control satisfaction in patients with total knee arthroplasty". Lower scores of VAS values were recorded in all of the education groups compared to the control group. This difference was observed more ex- 
plicitly on the third day, and VAS values showed interruption at an earlier period in the experiment group, which also reported less pain compared to the control group. Pre-operation anxiety values of informed patients were also found to be lower. The results were defined as statistically significant $(p<0.05)$. In a study by Karayurt [27], which investigated the "effect of different preoperative education programs on the anxiety and pain levels of patients", the patients in the group that had received routine care reported the highest level of pain. Pain levels were lowest in the group that had received education.

\section{Conclusions and Suggestions}

Lack of information related to possible pre-operation and post-operation conditions increases the anxiety level of patients. This causes post-operative emotional problems and a more intense sense of pain. Therefore, the following suggestions may be introduced for nurses and researchers:

- Including pre-operation education, which is not practiced at all in most hospitals or is practiced only in an unplanned way in some, into nursing applications;

- Allocating time to the patient during the pre-operation period, establishing a one-to one communication with the patient and allowing him/her to express his/ her feelings and thoughts;

- Providing patients pre-operatively with written information and instructions that will be followed during their stay in the hospital.

\section{Contributions}

Study design: NK, FC data analysis: NK manuscript preparation: NK,

\section{References}

[1] L. Birol, "Period of Nursery Izmır," 7th Edition, Etki Press, 2005, pp. 14-15.

[2] T. Şanli, "The Dimensios of İnterpersonal Reletion Ships in Nursey," Open Education Faculty Publications, Eskise hir, 1991, pp. 20-40.

[3] R. Yardakçi and N. Akyolcu, "The Effect of the Visits Made Preoperation on the Patients' Anxiety Level," The Turkish Journal of Research and Development in Nursing, Vol. 1, No. 2, 2004, pp. 7-14.

[4] F. Erdil and N. Özhan Elbaş, "Medical-Surgical Nursing," Desing Ofset, Ankara, 2001, pp. 98-136.

[5] M. Mitchell, "Anxiety Management: A Distinct Nursing Role in Day Surgery," Ambulatory Surgery, Vol. 8, No. 3, 2000, pp. 119-127. doi:10.1016/S0966-6532(99)00061-X

[6] M. K. Elkin, A. G. Perry and P. A. Potter, "Nursing
Interventions \& Clinical Skills," 3rd Edition, Mosby, St. Louis, 2004, pp. 491-507.

[7] C. Cimilli, “Anxiety in Surgery," The Journal of Clinical Psychiatry, No. 4, 2001, pp. 182-186.

[8] N. Kuğu, Ö. Berkan, G. Akyüz and O. Doğan, "The Anxiety and Depression Levels of Operated and Non-operated Patients with Chronic Peripheric Vascular Disease," Anatolian Journal of Psychiatry, Vol. 2, No. 4, 2001, pp. 213-221.

[9] N. Öner and A. Le Compt, "State Trait Inventory in Handbook," Boğaziçi University Publication, Istanbul, Vol. 333, 1985, pp. 1-26.

[10] G. Kocaman, "Nursing Process in Pain," Saray Medical Bookstore, İzmir, 1994, pp. 175-196.

[11] B. L. Chrıstensen, "Pain Management, Comfort, Rest, and Sleep," In: B. L. Christensen and E. O. Kockrow, Eds., Mosby, St. Louis, 2003, pp. 308-324.

[12] J. H. Watt-Watson and M. I. Donovan, "Pain. Management-Nursing Perpective," Mosby Year Book, Inc., St. Louis, 1992, pp. 401-409.

[13] M. Mc Caffery, "Nurses Lead the Way to New Priorites,' American Journal of Nursing, No. 10, 1990, pp. 45-49.

[14] B. K. Timby, "Fundamental Skills and Concepts in Patient Care," 6th Edition, Lippincott Williams \& Wilkins, Philedelphia, 1996.

[15] H. M. Rahman and J. Beattie, "Managing Post-operative Pain," The Pharmaceitical Journal, Vol. 275, No. 30, 2005, pp. 145-146.

[16] F. V. Abbott, K. Gray-Donald, M. J. Sewitch, C. C. Johnston, Linnda, M. E. Jeans, "The Prevalence of Pain in Hospitalized Patients and Resolution over Six Months," Pain, Vol. 50, No. 1, 1992, pp. 15-28. doi:10.1016/0304-3959(92)90108-N

[17] E. C. J. Carr, "Postoperative Pain: Patients' Expectations and Experiences," Journal of Advanced Nursingm, Vol. 15, No. 1, 1990, pp. 89-100. doi:10.1111/j.1365-2648.1990.tb01677.x

[18] M. F. Walding, "Pain, Anxiety and Powerlessness," Journal of Advanced Nursing, Vol. 16, No. 4, 1991, pp. 388-397. doi:10.1111/j.1365-2648.1991.tb03427.x

[19] G. Özalp, R. Sarıglu, G. Tuncel, K. Aslan and N. Kadiogullari, "Preoperative Emotional Satates in Aptients with Breast Cancer and Posoperative Pain," Acta Anaesthesiol Scand, Vol. 47, No. 1, 2003, pp. 26-29.

[20] W. Couma, A. P. Schmidt, C. N. Schneıder, J. Bergmann, C. W. Iwamoto, D. Benderre and M. B. C. Ferreıre, "Risk Factors for Preorerative Anxiety in Adults," Acta Anaesthesiol Scand, Vol. 45, No. 3, 2001, pp. 298-307.

[21] M. Lepczyk, "Timing of Preoperative Patient Teaching," Journal of Advanced Nursing. Vol. 15, No. 3, 1990, pp. 300-306. doi:10.1111/j.1365-2648.1990.tb01817.x

[22] S. O'Conner-Von, "Preparation of Adolescents for Outpatient Surgery: Using an Internet Program," AORN Journal, Vol. 87, No. 2, 2008, pp. 374-378. doi:10.1016/j.aorn.2007.07.024

[23] N. Karabulut and D. Arikan, "The Ifluence of Different 
Education Programmes Applied before Abdomen Operation on the Anxiety Level of the Child and the Mother. II," National/International TSK Nursing of Congress Papers, 25-27 May 2005.

[24] D. Miner, "Preoperative Outpatient Education," Nursing Management, Vol. 21, No. 12, 1990, pp. 27-29. doi:10.1097/00006247-199012000-00015

[25] N. Bölükbaş, "The Expectations of Surgical Patients from Nurses," Journal of Nursing, No. 20, 1991, pp. 81-86.

[26] A. Luck, S. Pearson, G. Maddern and P. Hewett, "Effect of Video İnformation on Precolonoscopy Anxiety and Knowledge: A Randomised Trial," The Lancet, Vol. 354, No. 9195, 1999, pp. 2032-2035. doi:10.1016/S0140-6736(98)10495-6

[27] Ö. Karayurt, "Effects of Different Preoperative Teaching Programmes on the State Anxiety and Pain Level," Journal of Cumhuriyet University Nursing School, Vol. 2, No. 1, 1998, pp. 20-26.

[28] K. Sümbüloğlu and V. Sümbüloğlu, "Biostatistics," Şahin Press, Ankara, 1997.

[29] G. Aksakoğlu, "Data Analysis: According to Data Analysis Methods for the Selection of the Average Comparison of Measurement," Health Research Methods and Analysis Methods, Dokuz Eylül University Publisher, Izmir, 2001, pp. 212-284.

[30] S. Erdine, "Pain," Nobel Medical Bookstore, Istanbul, Alemdar Offset Savaş Bindery, 2000, pp. 37-40.

[31] J. F. Cassady, T. T. Wysocki, K. M. Miller, D. D. Cancel and N. Izenberg, "Use of Preanesthetic Video for Facilitation of Parental Education and Anxiolysis before Pediatric Ambulatory Surgery," Anesthesia and Analgesia, Vol. 88, No. 2, 1999, pp. 246-250.

[32] P. A. Potter and A. G. Perry, "Basic Nursing," 3th Edition, Mosby Year Book, St. Louis, 1995, pp. 3-24.

[33] Ö. Ergin, "Instructional Technolog and Communication,"
Tegem Publication, Ankara, 1995, p. 102.

[34] A. Akkaş, "Determinibg the Anxiety Levels of Patients during the Pre-operative Period and the Factors Which May Cause Anxiety," The Turkish Journal of Research and Development in Nursing, No 1, 2001, pp. 23-29.

[35] K. Asilioglu and S. S. Celik, "The Effect of Preoperative Education on Anxiety of Open Cardiac Surgery Patients," Patient Education and Counseling, Vol. 53, No. 1, 2004, pp. 65-70. doi:10.1016/S0738-3991(03)00117-4

[36] L. Yorulmaz and T. Özbayir, "The Pre-operative and Post-perative Anxiety Level of Patients Who Would Undergo Laparoscopic Cholecystectomy," National Surgery Congress, Congress book for surgical nursing section of panels and papers, Antalya, 2002, pp. 319-324.

[37] A. Roth-Isıkeit, E. Ocklitz, S. Brückner, A. Ros, L. Dibbelt, J. H. Friedrich, et al., "Development and Evaluation of a Video Program for Presentation Prior to Elective Cardiac Surgery," Acta Anaesthesiologica Scandinavıca, Vol. 46, No. 4, 2002, pp. 415-423.

[38] S. Doering, H. Behensky, G. Rumpold, D. S. Schatz, S. Rössler, B. Hofstötter, et al., "Videotape Preparation of Patients before Hip Replacement Surgery İmproves Mobility after Three Months," Zeitschrift Für Psychosomatische Medizin Und Psychotherapie, Vol. 47, No. 2, 2001, pp. 140-152.

[39] A. Özberksoy and T. Özbayir, "The Effect of İnformative and Educative Nursing Approaches on Postoperative Anxiety and Pain in Patients with Breast Cancer," Surgical and Operating Room Nurse in Congress Papers, Ege Universty Press, Izmir, 2007, p. 211.

[40] M. Sjöling, G. Nordahl, N. Olofsson and K. Asplund, "The Impact of Preoperative İnformation on State Anxiety, Postoperative Pain and Satisfaction with Pain Management," Patient Education and Counseling, Vol. 51, No. 2, 2003, pp. 169-176. doi:10.1016/S0738-3991(02)00191-X 